\title{
Service provision for liver disease in the UK: a national questionnaire-based survey
}

\author{
R Scott, M Williams, A Lawson, A Austin and J Freeman
}

\begin{abstract}
The National Plan for Liver Services in 2009 called for a review of current liver services across the UK to identify areas of good and poor provision. We present the results of a national questionnaire survey of liver services, which focussed on staffing and training, access to key facilities and clinical management of liver disease. Areas of good practice include the increased proportion of consultants who trained at a liver centre, the introduction of specific liver clinics and the widespread use of terlipressin and antibiotics for variceal bleeding. Areas of poor practice include limited access to alcohol psychiatry services and transjugular intrahepatic portosystemic shunts (TIPS) and limited recording of outcome measures or patient databases. Wide variation in the clinical management of serious liver diseases supports the need for managed clinical networks. These results will help to guide the development of standards of care for liver services across the UK.
\end{abstract}

KEY WORDS: autoimmune hepatitis, hepatitis, liver disease, portal hypertension, service provision

\section{Introduction}

The burden of liver disease is increasing in the UK. ${ }^{1}$ Key drivers for the growing number of liver deaths are the rising prevalences of alcoholic liver disease, viral hepatitis and fatty liver disease. ${ }^{2}$ In 2009, the British Association for the Study of the Liver (BASL) and British Society of Gastroenterology (BSG) (Liver Section) published a National Plan for Liver Services. ${ }^{2}$ This report called for a review and restructuring of the provision of liver services in the UK. Previous reports of liver service provision in both specialist liver units ${ }^{3}$ and district general hospitals (DGHs) ${ }^{4}$ found significant deficiencies. The first key recommendation of the National Plan for Liver Services was therefore to call for an up-to-date review of the provision of liver services in the UK to identify areas of good and poor service provision and to define realistic standards of care.

\section{Methods}

An electronic questionnaire was sent to one consultant gastroenterologist in each of the hospitals in the UK. Consultants

R Scott, research fellow; M Williams, specialty registrar; A Lawson, hepatology consultant; A Austin, hepatology consultant and J Freeman, hepatology consultant

Derby Digestive Diseases Centre, Royal Derby Hospital were identified from a list of BSG members and the first listed member from each hospital was included in the survey. The recipients were asked to forward the survey to the person in charge of hepatology services in that hospital. Data were collected based on best estimates from the respondent. Information was sought about staffing levels, facilities and the management of acute and chronic conditions, namely variceal bleeding, hepatorenal syndrome, hepatitis $\mathrm{C}$ and autoimmune hepatitis.

\section{Results}

In total, 106/250 (43\%) hospitals replied to the questionnaire (71 DGHs, 30 teaching hospitals and five transplant centres). The median hospital catchment population was 300,000 (range $35,000-750,000)$ in DGHs and 450,000 (300,000-5 million) in teaching hospitals. Table 1 shows the median levels of consultant staffing. Overall, $92 \%$ of consultants felt that the workload due to liver disease is increasing. Across all sites, $61 \%$ of hospitals held specific hepatology clinics.

Table 2 shows the support facilities available to consultants from other colleagues. Overall, $89 \%$ of the specialist nurse posts are funded exclusively by the NHS, $2 \%$ wholly by drug companies and $9 \%$ by a combination.

\section{Facilities}

In total, $66 \%$ of respondents perceive that access to renal services is easy compared to $80 \%$ accessing their local Intensive Care Unit (ICU). Of the ICUs perceived to be difficult to access, the most common reason given for this difficulty was a perceived poor outcome $(67 \%)$, with some feeling that intensivists lacked expertise in managing patients with liver disease $(53 \%)$ or discriminated against patients with alcoholic liver disease (28\%).

\section{Liver biopsies}

Ultrasound-assisted liver biopsies are available in all hospitals through the radiology department and all departments are aware of the BSG's guidelines, with $98 \%$ of departments reporting that they follow these guidelines. In contrast, transjugular liver biopsies are available in $80 \%$ of teaching hospitals but only $28 \%$ of DGHs. Of the 20 DGHs that provide this service, four units perform 10 or more procedures per year. This contrasts with the 28 teaching hospitals, which perform a median number of 11 (range 2-100). 
Table 1. Staffing and workload.

\section{District general hospital}

Gastroenterologists per hospital (range)

Hepatologists per hospital (range)

Intend to appoint a hepatology consultant

Years respondent spent in dedicated hepatology training as registrar (range)

Respondents who trained at a regional liver centre (\%)

Outpatient workload attributable to liver disease (\%, range)

Inpatient workload attributable to liver disease (\%, range)

Respondents that feel liver workload is increasing (\%)

Hospitals that hold specific liver clinics (\%)
$4(0-11)$
$0(0-1)$
13
$1(0-5)$
69
$22(0-70)$
$40(5-90)$
90
51

\section{Tertiary hospital}

$7(3-15)$

$1(0-10)$

51

$1.75(0-7)$

77

$46(5-100)$

$58(10-100)$

97

83

\section{Table 2. Percentage of consultants reporting access to categories} of support and facilities.

\begin{tabular}{|c|c|c|}
\hline Liver specialist nurse & 58 & 74 \\
\hline $\begin{array}{l}\text { Radiologist with specific } \\
\text { liver interest }\end{array}$ & 32 & 69 \\
\hline $\begin{array}{l}\text { Pathologist with specific } \\
\text { liver interest }\end{array}$ & 21 & 83 \\
\hline $\begin{array}{l}\text { Liver multidisciplinary } \\
\text { team meetings }\end{array}$ & 24 & 66 \\
\hline Alcohol support team & 51 & 71 \\
\hline Alcohol psychiatrist & 26 & 54 \\
\hline \multicolumn{3}{|l|}{$\begin{array}{l}\text { Easy access for patients } \\
\text { with decompensated liver } \\
\text { disease }\end{array}$} \\
\hline Renal services & 62 & 75 \\
\hline High-dependency care & 62 & 74 \\
\hline Intensive care & 79 & 86 \\
\hline $\begin{array}{l}\text { Access to transjugular } \\
\text { liver biopsy }\end{array}$ & 28 & 80 \\
\hline $\begin{array}{l}\text { Access to transjugular } \\
\text { intrahepatic portosystemic } \\
\text { shunt (TIPS) }\end{array}$ & 24 & 97 \\
\hline
\end{tabular}

Although most respondents agreed that transjugular biopsies should be used in patients with platelet counts $<50 \times 10^{9} / 1$ or international normalised ratios (INRs) $>1.5$, only two reported using a threshold bilirubin level and six used a threshold creatinine level.

Table 3 shows the management of a variety of acute and chronic liver conditions, including hepatitis $\mathrm{C}$, variceal bleeding and autoimmune hepatitis.

\section{Hepatitis C}

Infectious disease consultants and gastroenterologists continue to treat the majority of cases (69\%) except in liver units, where most patients are treated by hepatologists. A large discrepancy exists between the laboratory provision for hepatitis $\mathrm{C}$ between

\section{Table 3. Clinical management of liver disease in 2010 .}

\begin{tabular}{|c|c|c|}
\hline & $\begin{array}{l}\text { District general } \\
\text { hospital }\end{array}$ & $\begin{array}{l}\text { Tertiary } \\
\text { hospital }\end{array}$ \\
\hline \multicolumn{3}{|l|}{ Chronic hepatitis C } \\
\hline Treat HCV (\%) & 58 & 68 \\
\hline $\begin{array}{l}\text { Follow NICE } \\
\text { guidelines (\%) }\end{array}$ & 62 & 63 \\
\hline Follow local guidelines (\%) & 21 & 41 \\
\hline $\begin{array}{l}\text { Treat genotype } 2 \text { or } 3 \\
\text { without liver biopsy (\%) }\end{array}$ & 81 & 87 \\
\hline $\begin{array}{l}\text { Funding limited by } \\
\text { trust (\%) }\end{array}$ & 18 & 22 \\
\hline \multicolumn{3}{|l|}{ Variceal bleeding } \\
\hline $\begin{array}{l}\text { Provide acute bleed } \\
\text { service (\%) }\end{array}$ & 54 & 89 \\
\hline $\begin{array}{l}\text { Routinely give antibiotic } \\
\text { prophylaxis (\%) }\end{array}$ & 97 & 100 \\
\hline $\begin{array}{l}\text { Sengstaken tubes } \\
\text { inserted per year } \\
\text { (number, range) }\end{array}$ & $4(0-20)$ & $6(2-100)$ \\
\hline \multicolumn{3}{|l|}{ Autoimmune hepatitis } \\
\hline $\begin{array}{l}\text { Tacrolimus used in } \\
\text { difficult cases (\%) }\end{array}$ & 15 & 49 \\
\hline $\begin{array}{l}\text { Mycophenolate mofetil } \\
\text { used in difficult cases (\%) }\end{array}$ & 56 & 69 \\
\hline $\begin{array}{l}\text { Watch and wait in } \\
\text { difficult cases (\%) }\end{array}$ & 9 & 11 \\
\hline $\begin{array}{l}\text { Routinely perform } \\
\text { follow-up liver biopsies (\%) }\end{array}$ & 25 & 26 \\
\hline \multicolumn{3}{|l|}{ Hepatorenal syndrome } \\
\hline Use terlipressin (\%) & 97 & 94 \\
\hline Use albumin (\%) & 87 & 97 \\
\hline
\end{tabular}

$\mathrm{HCV}=$ hepatitis $\mathrm{C}$ virus.

DGHs and teaching hospitals: hepatitis C genotyping is available in $20 \%$ of DGHs and $57 \%$ of teaching hospitals, and, similarly, estimation of viral load is available in $20 \%$ and $63 \%$, respectively. 


\section{Autoimmune hepatitis}

All hospitals surveyed use prednisolone and azathioprine as first-line treatments for autoimmune hepatitis. Large discrepancies exist between the treatments received by patients who do not respond to this initial therapy and those who are intolerant of azathioprine, with most cases being referred to a liver unit at this stage ( $74 \%$ of cases in DGHs). If second-line treatment is considered, it is more likely to be mycophenolate mofetil ( $56 \%$ of cases in DGHs and 62\% in teaching hospitals) than tacrolimus (15\% of cases in DGHs and $42 \%$ in teaching hospitals). Interval biopsies are performed infrequently, even in liver centres ( $25 \%$ overall).

\section{Variceal haemorrhage}

The use of terlipressin has been widely adopted (100\% overall). Vasoconstrictor therapy is continued for a median of 3 (range 2-10) days. Despite this, a median of 4.5 (range 0-100) Sengstaken-Blakemore tubes are inserted at each hospital every year. Similarly, the routine use of prophylactic antibiotics is now widespread. However, significant variation exists in the antibiotic regimens used: $52.1 \% \beta$-lactams, $33.3 \%$ cephalosporins, $12.5 \%$ quinolones and $2.1 \%$ other antibiotics.

In the event of a rebleed, $98 \%$ of respondents repeat the endoscopy. If this is unsuccessful, most patients are referred for a transjugular intrahepatic portosystemic shunt (TIPS) procedure ( $83 \%$ of patients in DGHs, $85 \%$ in teaching hospitals). As TIPS is much less accessible in the DGH setting (24\%), most cases are referred locally. Only 20 hospitals keep outcome data on variceal haemorrhage, which has an estimated mortality of $20 \%$ (range $5-60 \%$ ).

\section{Hepatorenal syndrome}

A median of 15 (1-250) cases per unit are seen each year. The use of terlipressin is fairly universal (96\%). Although the use of albumin is widespread (90\%), more than $13 \%$ of DGHs are still not using it in this setting. The most common reason for not using terlipressin is a perceived lack of efficacy (3\%), followed by inexperience in its use (1\%) and cost (1\%). The dose of terlipressin given over 24 hours varies from patient to patient in each centre, ranging from $2 \mathrm{mg}$ to $8 \mathrm{mg}$. Only a very small minority of these patients are referred to a liver centre, with a median referral rate of one per year from DGHs.

\section{Liver transplantation}

Most consultants (97\%) felt that access to transplant units is good. The median number of patients referred each year for liver transplantation is five (range 0-300) per unit. Only a minority of DGHs complete a comprehensive pre-transplant work up locally (19\%). The median number of post-transplant patients under local follow-up is just four (range 0-100\%) in DGHs. This suggests that most patients in DGHs still have to travel to their transplant centre on a regular basis.
Only $40 \%$ of all units have a shared protocol with their local transplant unit.

Overall this survey has found $25 \%$ of units now have a database of patients with liver disease compared to $17 \%$ with databases of patients with gastrointestinal disease. About half (55\%) of DGHs and three-quarters (83\%) of teaching hospitals are aware of the National Plan for Liver Services.

\section{Discussion}

The National Plan for Liver Services called for the division of liver services into a three-tiered system: tier 1 provides 'minimal liver services' such as a clinic, tier 2 'accept[s] referrals at level short of transplantation' and tier 3 comprises transplant centres. How these tiers are defined is contentious, vague and poorly defined. In the survey, $51 \%$ of DGHs and $83 \%$ of teaching hospitals hold specific hepatology clinics and 19\% of DGHs and $46 \%$ of teaching hospitals perform full work-up of patients before referral for liver transplant. If a hospital required three full-time consultant hepatologists to constitute a tier 2 hospital, only 6/101 (6\%) hospitals would be included. Our survey asked units to self-classify, with $7 / 101$ hospitals other than the five transplant centres considering themselves a liver unit. To allow comparison and make the data accessible, we have categorised hospitals into DGHs and teaching hospitals, accepting this does not adhere to the three-tiered model proposed.

There are no clearly defined requirements for a minimum number of tier 2 hospitals. To establish national clinical networks, this needs to be addressed - perhaps, for example, based on a ratio of three tier 2 hospitals to one transplant centre. The figures presented are estimates of the respondents and may therefore be influenced by reporter bias. Previous surveys have used similar data, so it is hoped that the data will remain valuable and be appropriate for comparison.

In an era of increasing mortality from liver disease, it is clear that hepatology services in the UK remain patchy. The BSG estimated that the workload for an average DGH required six full-time consultant gastroenterologists. ${ }^{5}$ Current levels are improving ${ }^{4}$ but two-thirds of this remain in DGHs, which will restrict opportunities for consultants to subspecialise as hepatologists. Training opportunities in hepatology were restricted historically, and this is reflected in the low proportion of consultants who trained at a liver unit in the past. ${ }^{4}$ The picture is changing, with most consultants now experiencing at least a year in a liver centre and at least one consultant in each hospital having an interest in hepatology. It is widely acknowledged that the burden of liver disease is increasing generally in both inpatient and outpatient settings, but only half of DGHs hold specific hepatology clinics.

The infrastructure to run a liver service is not in place outside liver units, with significant shortages in radiology, pathology, alcohol support services and multidisciplinary meetings. The importance of these facilities in preventing admissions and saving money has been published. ${ }^{6}$ Despite the publication of the Models of care for alcohol by the Department of Health in 2007,7 alcohol psychiatry service structures are poorly developed, with care 
pathways often ill defined. Further reports from the National Institute for Health and Clinical Excellence (NICE) ${ }^{8-10}$ have highlighted ongoing deficiencies in alcohol psychiatry services and suggested ways in which they could be improved. Without addressing this unmet need, we are unlikely to reduce the impact of alcohol, and indeed food, addiction on liver services in the future.

The utility of nurse specialists in delivering liver services for hepatitis $\mathrm{C}$ has been highlighted, ${ }^{11}$ but the availability of nurse specialists, although improved compared to $2009,{ }^{4}$ remains limited to half of DGHs.

The availability of ultrasound-assisted liver biopsies is excellent and universal, representing a significant improvement. ${ }^{4}$ Access to transjugular liver biopsies (TJBs) remains limited in DGHs, with only a quarter of hospitals offering this approach. The majority of teaching hospitals and all liver units offer this facility. This may reflect the fact that most DGHs are able to refer locally to larger hospitals where TJBs are performed. This was not asked in our survey but the patchiness of services does highlight the unequal distribution of facilities available to patients in a DGH. Those centres offering TJBs have similar criteria used when determining which patients require this approach, reflecting increased familiarity and adherence to guidelines.

Variceal bleeding and hepatorenal syndrome are associated with high mortality and their management includes evidencebased approaches. ${ }^{12-14}$ Only half of DGHs offer an acute gastrointestinal bleed service, which reflects the findings of other surveys. ${ }^{15,16} \mathrm{~A}$ recent study showed that no change in mortality is achieved with an emergency gastrointestinal bleed service. ${ }^{15}$ Most hospitals use banding and sclerotherapy and administer terlipressin. The use of antibiotic prophylaxis has been shown to reduce mortality in variceal bleeding. ${ }^{17}$ Although almost all respondents routinely use antibiotics, a significant proportion are using untested combinations that may not offer the necessary spectrum of cover, and the spectrum used remains broad. Salvage therapy for recurrent variceal bleeding seems to be addressed adequately, although it is interesting that some units use much higher number of Sengstaken-Blakemore tubes than others. Poor access to TIPS in DGHs probably reflects that most refer to larger local hospitals which do offer a TIPS service. This was not directly asked in our survey. It does, however, highlight the unequal distribution of facilities available to patients in a DGH. The much higher rate of DGHs that would refer rebleeders for TIPS (83\%) suggests this is the case. In addition, $17 \%$ of DGHs would not refer for TIPS despite evidence that early use may be beneficial in the context of variceal haemorrhage. ${ }^{18}$

If untreated, hepatorenal syndrome is associated with $90 \%$ mortality. Terlipressin leads to improved renal function in about two-thirds of cases and has been adopted by many units for the treatment of hepatorenal syndrome. ${ }^{19}$ The dose and duration used is highly variable and the optimal regimen remains unclear: studies have used between $0.5 \mathrm{mg}$ and $2 \mathrm{mg}$ every 4-6 hours, with no adequate dose comparisons. The addition of albumin has been shown to improve the effect of terlipressin, and it is disappointing that more than $10 \%$ of DGHs still use terlipressin alone. This continues to be the case despite the issue being highlighted in a survey of DGHs in 2009. ${ }^{4}$

It is possible to predict short-term mortality in patients with cirrhosis and the implementation of local guidelines may improve acceptance of patients with liver disease into the ICU, ${ }^{20}$ which continues to be a problem.

Hepatitis $\mathrm{C}$ infection will become an increasing part of the workload for the NHS, with $0.5 \%$ of the population in the UK being affected. ${ }^{2}$ Although the prevalence of hepatitis $\mathrm{C}$ is now falling, the proportion of patients presenting in clinical practice with advanced disease and the associated complications will increase. In the future, more patients will have cirrhosis and treatment options may result in more adverse effects and lower response rates without specialist input. Most consultants remain unable to provide a complete hepatitis $\mathrm{C}$ service, lacking the supporting services required by the National Plan for Liver Services ${ }^{2}$ and the NICE guidelines. ${ }^{22}$ It is encouraging that most hospitals do now follow NICE guidelines for the treatment of hepatitis C.

\section{Conclusion}

The survey shows that the provision of liver services at a national level is insufficient to meet current demand and remains ill equipped to cope with the increasing burden of liver disease. Marked deficiencies exist in consultant numbers and support from nurse specialists and allied medical specialities such as radiology, pathology and psychiatry. Access to facilities including laboratory tests and interventional radiology is patchy. Wide variation remains in the management of many common liver diseases, such as hepatitis C, variceal haemorrhage, autoimmune hepatitis and hepatorenal syndrome. Most hospitals do not have databases of their patients with liver disease and outcome measures for many interventions are lacking, which makes it difficult to compare the impact of local variations in patient care. Although previous surveys have shown service provision in liver centres and DGHs, ${ }^{3,4}$ this survey is the largest published to date and shows that resources available in many hospitals are extremely patchy and confirms that resources available at many DGHs remain limited. The data support the need for implementation of the National Plan for Liver Services and the formation of managed clinical networks in hepatology, even in an environment of economic frugality.

\section{References}

1 World Health Organization. WHO European health for all database. Geneva: WHO, 2009.

2 British Association for the Study of the Liver and British Society of Gastroenterology (Liver Section). A time to act: improving liver health and outcomes in liver disease. London: National Plan for Liver Services UK, 2009.

3 Williams R. Provision of specialist liver services in England. 2004. www.bsg.org.uk/pdf_word_docs/hepservices.doc [Accessed 21 January 2012].

4 Williams MJ, Salmon C, Austin AS, Freeman JG. Services for liver disease in district general hospitals in the UK: a national questionnairebased survey. Clin Med 2009;9:26-9. 
5 Royal College of Physicians. Consultant physicians working with patients: the duties, responsibilities and practice of physicians in general medicine and the specialities, 3rd edn. London: RCP, 2005.

6 Moriarty KJ, Cassidy P, Dalton D et al. Alcohol-related disease: meeting the challenge of improved quality of care and better use of resources. London: British Society of Gastroenterology, British Association for Study of the Liver, Alcohol Health Alliance UK, 2010.

7 Department of Health (England) and the devolved administrations. Drug Misuse and Dependence: UK Guidelines on Clinical Management. London: Department of Health (England), the Scottish Government, Welsh Assembly Government and Northern Ireland Executive, 2007.

8 National Institute for Health and Clinical Excellence. Alcohol use disorders: preventing the development of hazardous and harmful drinking. Public health guidance 24. London: NICE, 2010.

9 National Institute for Health and Clinical Excellence. Alcohol-use disorders. Clinical guideline 115. London: NICE, 2011. www.nice.org.uk/nicemedia/live/13337/53191/53191.pdf [Accessed 21 January 2012]

10 National Institute for Health and Clinical Excellence. Alcohol use disorders: diagnosis and clinical management of alcohol-related physical complications. Clinical guideline 100. London: NICE, 2010.

11 Dusheiko G, Rosenberg W, Miles A, eds. The effective management of hepatitis $C$ infection. UK Key Advances in Clinical Practice Series. London: Aesculapius Medical Press, 2001.

12 McCormick PA, O'Keefe C. Improving prognosis following a first variceal haemorrhage over four decades. Gut 2001;49:682-5.

13 Laine L, Planas R, Nevens F et al. Treatment of the acute bleeding episode. In: Franchis RD, ed. Portal Hypertension IV: Proceedings from the Fourth Baveno International Consensus Workshop. Oxford: Blackwell Publishing, 2006:217-42.

14 Cárdenas, Ginès P. Hepatorenal syndrome: current concepts. In: Franchis RD, ed. Portal Hypertension IV: Proceedings from the Fourth
Baveno International Consensus Workshop. Oxford: Blackwell Publishing, 2006:201-42.

15 Hearnshaw SA, Logan RF, Lowe D et al. Use of endoscopy for management of acute upper gastrointestinal bleeding in the UK: results of a nationwide audit. Gut 2010;59:1022-9.

16 Gyawali P, Suri D, Barrison I et al. A discussion of the British Society of Gastroenterology survey of emergency gastroenterology workload. Clin Med 2007;7:585-8.

17 Bernard B, Grangé JD, Khac EN et al. Antibiotic prophylaxis for the prevention of bacterial infections in cirrhotic patients with gastrointestinal bleeding: a meta-analysis. Hepatology 1999;29:1655-61.

18 García-Pagán JC, Caca K, Bureau C et al. Early use of TIPS in patients with cirrhosis and variceal bleeding. N Engl J Med 2010;362:2370-9.

19 Ginès $\mathrm{P}$, Torre $\mathrm{A}$, Terra $\mathrm{C}$, Guevara $\mathrm{M}$. Review article: pharmacological treatment of hepatorenal syndrome. Aliment Pharmacol Ther 2004;20(Suppl 3):57-62.

20 Cholangitas E, Senzolo M, Patach D et al. Risk factors, sequential organ failure assessment and model for end-stage liver disease scores for predicting short term mortality in cirrhotic patients admitted to intensive care unit. Aliment Pharmacol Ther 2006;23:883-93.

21 Department of Health. Hepatitis C strategy for England. London: DH, 2002.

22 National Institute for Health and Clinical Excellence. Peginterferon alfa and ribavirin for the treatment of chronic hepatitis $C$. Technology appraisal guidance 200. London. NICE, 2010.

Address for correspondence: Dr J Freeman, Derby Digestive Diseases Centre, Royal Derby Hospital, Uttoxeter Road, Derby, DE22 3NE.

Email: j.freeman115@btinternet.com

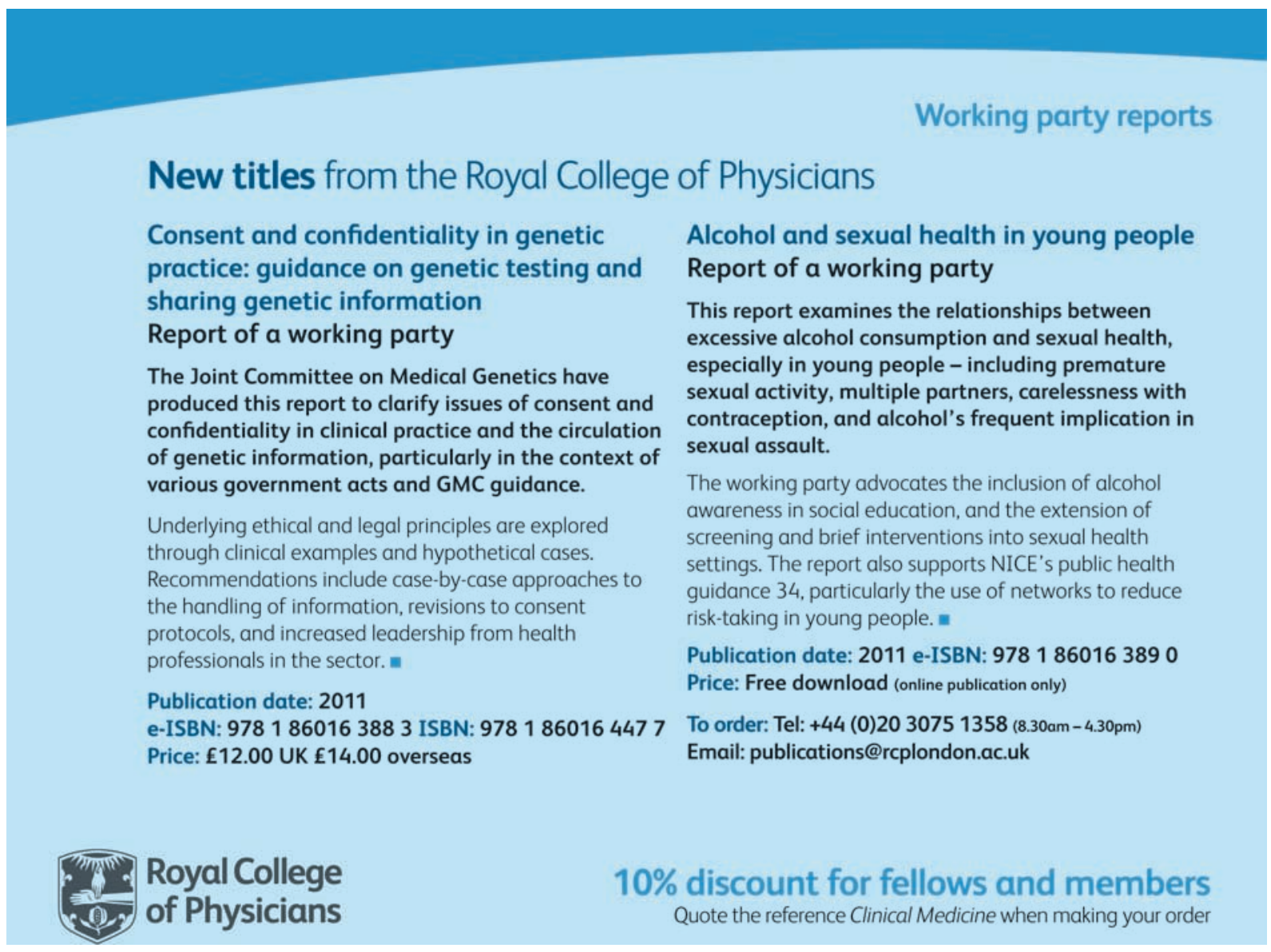

